\title{
Digital movie clothing with film clothing visual art representation
}

\author{
Yugang Chen ${ }^{1, a}$ \\ ${ }^{1}$ Jiangxi Institute of Fashion Technology, Jiangxi, Nanchang, 330201 \\ a28941204@qq.com
}

Keywords: The visual arts; Film costume; Digital movie; film

\begin{abstract}
Visual art appearance also is the reality of things or events actually left by the image in the people on the brain. The application of digital technology in film production, for the development of the film is a revolutionary change. Film costume design digital movie or film, must closely around the theme of the film as well as the character, image, mood changes. And digital movie costumes and film costume design though and his role is to serve the theme of the film's need, but because of the rules and requirements of the design and production quality is difference, so it bring people visual art representation differences too.
\end{abstract}

\section{The introduction}

Digital film produced in the ninety s, it is the product of computer information technology development. The continuous development of computer technology, for many traditional film cannot complete lens provides a possible, at the same time also makes the film making effect more perfect today, with the continuous development of computer technology, digital movie picture began moving into the direction of multi-dimensional three-dimensional, become one of the people's favorite entertainment. Digital movie fashion design in Europe and the United States is the world's leading position, while in our country is still a preliminary exploration stage, mainly refers to the art representation when things are not in front of people, in the brains of people will still form a specific image of the things. From the point of view of information, that is, information about real things or events, this information will give people a specific image. Digital cinema in the visual art representation of virtual clothing with movement, deep, imagination, memory, attention, and the characteristics of emotional, these visual art image is closely connected with traditional costumes in the reality of the image.

\begin{abstract}
About the introduction of digital movie clothing
Digital technology brought the unprecedented development in the middle of the 20th century, mankind also therefore drew the digital age, to some degree, it provide technical support to the digital development of the film. Costume design of digital movie was originally produced in the United States, at the same time, design prototype is basically heroism cartoon from the United States. The design methods of more traditional costume design, it focused more on the application of a variety of elements and the fusion, including color, style, material, structure, etc. On the production way, focusing on the use of various models of software and image synthesis technology, thus has a strong virtual sex, costume creators can give full play to your imagination for the design of random, but also must be restricted by reality of clothing prototype, enable it to meet people's aesthetic, conform to the need of film visual art expression.
\end{abstract}

\section{Digital movie clothing with film clothing visual art representation comparative analysis}

With the continuous development of society, "people-oriented, green environmental protection, energy saving" concept is deeply rooted in the hearts of the people, such as digital film making clothes very accord with the requirement of the construction of environment-friendly society in our country, also gave designers more imagination and creation of the heavens and the earth, for the development of the film industry, is also the new development opportunity. Digital movie clothing with film clothing existence very big difference, so bring people visual art representation there is also a very big difference. 
Design rules of comparative analysis. Digital movie clothing or film has its own clothing design principles and design rules, but they are to serve the theme of the film and the characters of shape, but the difference is that for traditional film's dress, the dress design more elegant style and pattern, color, fabric and other combination collocation, emphasizes the process of machining, but also pay more attention to study film era background, make the design of dress can reveal the historical and cultural, conform to the dress and garment materials of people at that time, all designs are through strict textual research, rather than on the basis of personal fantastical imagination.

After years of development, the movie costumes for film theme show that play the role of more and more important, by director is becoming more and more attention, for example, "Roman holiday", "cleopatra" and other well-known film, make a lot of evaluation, the clothing design of visual effect of reinforcement has played an immeasurable role, as shown in figure 1 . In addition, the traditional film costumes to some extent, play a role is to change the character of inner emotional world or the character of external, this was reflected in many works with the director, the film "the grand master", for example, the heroine of the gong, miss very strong-willed personality spirit, to avenge his father, do not hesitate to return the engagement, can even do lifelong not to marry, her character in the solitary cold at the time of its destruction, displayed in a fur coat is completely, as shown in figure 2. Film, for example, inside of the hunchback of Notre Dame DE Paris, have seen the audience should know, the clothing design is a very vulgar, ugly and coarse, but rather than the beauty of the soul have played an important role in contrast, making his beauty has been further sublimation.

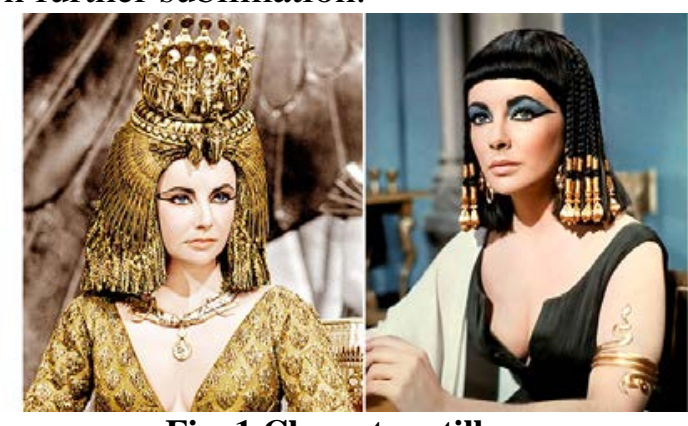

Fig. 1 Cleopatra stills

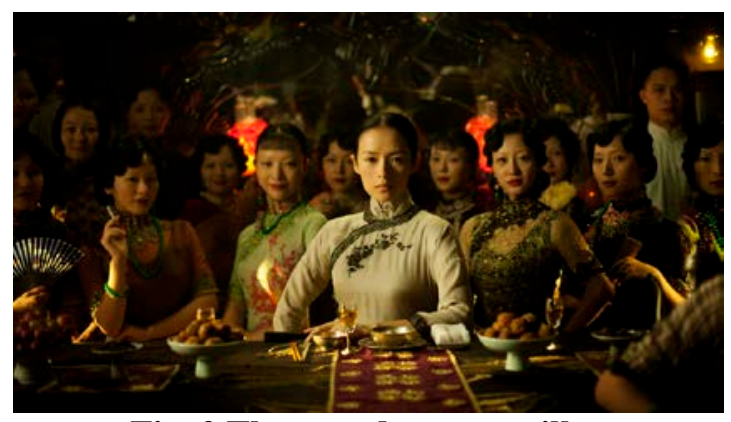

Fig. 2 The grand master stills

In traditional costumes in the movie the clothing structure and practicability of the has a higher request, if there is no macro design, details of the adjustment, expressed by the clothing style and the movie theme, no specific practical, so the whole movie tone will have deviation, directly affect the film's box office performance and quality. Digital movie costumes also must conform to the needs of the movie depicting characters, but as a result of digital movie clothing design a lot of time with the aid of certain computer special effects, and most of the time is to shape the image of hero. The current digital movie costumes, generally there are two main types, one is the actual wearing costumes, one is using the digital technology in the post-production dynamic virtual characters with clothing. The former and the traditional film dress little difference, so this paper mainly discusses the latter, namely digital virtual movie costumes. This dress is focused on the design and the design of apparel fabric, focuses on the use of color change to show the characters' emotional characteristics, at the same time pay attention to the use of light and shadow to render atmosphere, and smooth skin texture is compared commonly "cold", performance is generally aloof mood, with a very strong resistance, for example, the matrix, the film's tone is given priority to with "black", give people the visual effect from beginning to end is cold.

To sum up, on the design rules, the two are already there exist similarities and differences, similarities lies in the design of the two are in the service of the theme of the movie, and the need of character image design, the difference is that virtualization of digital movie costumes on creative design, the authors have greater freedom, digital film mostly focused on the science fiction film production, so its design generally has no real prototype, mostly designed for the purpose of shaping exaggerated the visual effect of tension, such as the sea of galle than inception ", "avatar" films such as the design of digital movie clothing high degrees of freedom, such as "spider-man", 
"pirates of the Caribbean" virtual clothing more dynamic effects in the movie, go up character in material with high imitation, attempt and clothing material close to reality, in the design, pay more attention to making effective use of resources.

The design requirements and the way comparative analysis. Film role of clothing is an important means of construction of visual art, film, its design is generally closely around role. While traditional film due to the finiteness of visual art, means, so it focused more on the role of clothing is used to reflect the identity of the characters, cater to the needs of the role mood and atmosphere.

In addition, the traditional film clothing especially some costume dramas, in roles costume design application, is more pay attention to the integration of the national culture characteristic elements, so the performance of the project, not only able to make films with ethnic characteristics, at the same time also can rise the effect in the spread of national history and culture, in order to make the garment design play a proper role in visual effect, for the protagonist in the film, the clothing design relatively delicate, also will be supplemented by other adornment, also can use the traditional arts and crafts, such as sequins, embroidery, printing and dyeing process. Liu xiaoqing's version of "empress wu", for example, the clothes will use a lot of embroidery craft processing, also with printing and dyeing technology, give a person the visual effect of the whole is both delicate and beautiful, very accord with wu zetian this character noble royal status.

In addition, the traditional movie character costumes, costumes, especially leading role in the mode of production, is almost pure hand-made, completely is according to the role of positioning, to make the style of dress, choose the color of the dress fabrics, clothing, etc. For digital movie costumes, have a lot of virtual sex, digital movie focused more on creating fantasy film visual effects, through various means of the application of science and technology, the characters in the film's dress and colour, nearly all action can implement virtualization, but it can be real to the audience's visual effect. Just because of this feature of digital film, so the design of the dress can almost no rules, can be fantastical imagination to reality, as long as the design result can meet the film builds atmosphere, the needs of the character image. But its prototype or from the reality of apparel modeling, fashion the some basic elements of component will not less, that still should follow the rules of art comes from life, or to have the certain historical authenticity, but digital movie character costumes in the film usually there's a certain function, become the protagonist in the film to show the important tool of ability. For example, "harry potter" the hero's dress there's a certain magic, so called magic robe, as shown in figure 3. Therefore, from a certain perspective, digital movie clothing functional let that located in clothing bring to people's visual effect, but in terms of use clothing to strengthen the visual effects, its much better than the traditional film, it's easier to give people the visual impact.

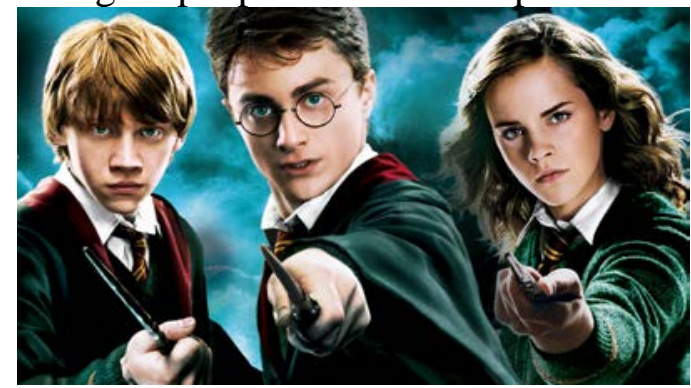

Fig. 3 Harry potter co-stars

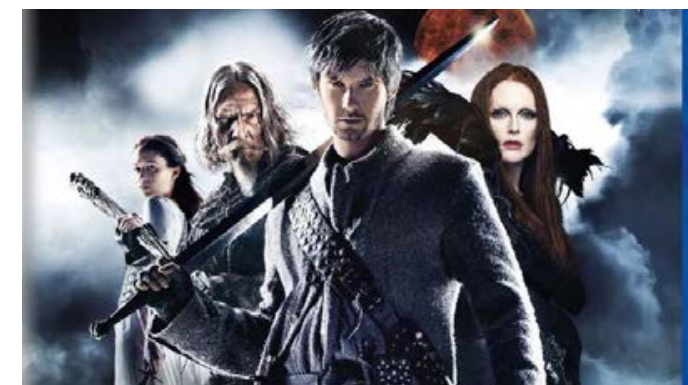

Fig. 2 War of the first seven: drop the stills

In the mode of production, the digital film role clothing design and manufacture can be almost completely divorced from reality, it can use the $3 \mathrm{~d}$ figure of computer software, will need expression, clothing modelling, the clothing color to adjust the virtual sex, such as, through the synthetic technology of the digital image films with preset all sorts of scenes, characters in the computer to carry on the synthesis, to render the effect of atmosphere of the film. For example the first seven: drop the wars, all sorts of warcraft exaggerated movements, and drop the magic of magic coat, etc., and the fight between people magic effects, etc., are the effect of the computer digital image synthesis. Generally speaking, the making way is through a variety of software model, to constantly synthesis need clothing visual effect, as shown in figure 4. 
What has been discussed above, we can know that the traditional film costumes and digital movie costumes on the requirements of the design is already there exist similarities and differences, similarities is all in the service of the role of shape, and the difference is that digital movie pay more attention to the dynamic visual effect, the traditional film costumes pay more attention to the authenticity of history and the use of national culture, on the design approach, both almost completely different, the traditional film costumes notice is manual mode of production, relies on the apparel design and production of materials in real life, but the digital movie clothing design and manufacture can be said to be completely virtual, using all kinds of apparel design and production model, designers can ignore the needs of real life and respect history, in his role as the basic standards, at the same time also can adjust the modelling freedom in design, does not need to consider cloth, cut out all sorts of problems, such as its more in line with the concept of building a conservation-minded society, so it brings the audience's visual effect often movement.

\section{Conclusion}

The development of computer information technology, make modern movie clothing has the very strong virtual sex, and give people the visual impact of the earthquake more powerful, more traditional movie clothing because of the limitation of technology basic focus is made by hand. As a result, it for the audience, more realistic life. This article focuses on the digital movie costumes and traditional film costumes on the visual representation of similarities and differences, hope to provide important reference value for related research.

\section{Reference}

[1] Keqi Lu. Theory of the story and the perfect combination of fashion design [J]. Contemporary films, 2014, (9).

[2] Yaqing Chen. Introduction to costume design and art fusion [J]. Journal of movie review, 2015 (7).

[3] Yajuan Shi; Jianping Guo. Movie costumes linguistics research [J]. Journal of drama literature, $2010(01)$. 